\title{
Spiritual Leadership and Job Satisfaction: A Proposed Conceptual Framework
}

\author{
Juhaizi Mohd Yusof, Izah Mohd Tahir* \\ Faculty of Business Management and Accountancy, Universiti Sultan Zainal Abidin (UniSZA), Terengganu, \\ Kuala Terengganu, Malaysia \\ *izah@unisza.edu.my
}

\begin{abstract}
The objective of this study is to propose a framework that relates spiritual leadership theories to job satisfaction in a multidimensional approach. The framework is designed based on the previous literatures. Spiritual leadership components that will be included in the study consist of vision, altruistic love, hope/faith, meaning, calling and membership. Job Descriptive Index (JDI) is adapted to measure job satisfaction. JDI provides five subscales that measure different facets of job satisfaction describing various aspects of the respondent's work experiences such as the work itself, pay/promotion, supervision, and coworkers. This study also included turnover intention in the framework to measure job dissatisfaction. In this study, nine hypotheses will be proposed based on the conceptual framework outlined.
\end{abstract}

Keywords: Conceptual framework, Spiritual Leadership, Job Satisfaction, Turnover Intention

\section{Introduction}

The success of the organizations depends very much on its human resource team. This should be nurtured and cared for optimum effectiveness and efficiency. Leaders and followers play very important role in any organizations. Organizations need effective leadership and employees to achieve their objectives. What is leadership? Barnett (2011) defined leadership as a process by which one individual influences others toward the attainment of group or organizational goals. It is a management function which is mostly directed towards people and social interaction, as well as the process of influencing people so that they will achieve the goals of the organization (Skansi, 2000; Barnett, 2011). Both leadership and management are assigned to set direction for the organization. Organizations cannot succeed without appropriate efforts and right commitment from their employees. The success in achieving its goals depends very much on managers and their leadership style. Leadership style can be viewed as a series of managerial attitudes, behaviours, characteristics and skills based on individual and organizational values, leadership interests and reliability of employees in different situations (Mosadeghrad, 2003). However, no one leadership style is ideal for every situation, since a leader may have knowledge and skills to act effectively in one situation but may not act as effectively in another situation (Mosadeghrad, 2003). To be effective, leaders must behave and use appropriate leadership styles to improve employee job satisfaction, commitment and productivity (Fry, 2003).

Most leadership theories; path-goal, charismatic, and transformational theories of leadership, although not explicitly focused at the strategic level, focus on motivating followers (Bass, 1990, Fry, 2003). However, Fry (2003) argued that previous leadership theories have focused in varying degrees on one or more aspects of physical, mental, or emotional elements of human interaction in organizations and neglected the spiritual component. Most leadership research focus less attention to spiritual issues and those spiritual qualities are commonly overlooked in relation to leadership positions (Thompson, 2000). Fairholm (1996) stated that nourishing the spirit at work requires leaders to consider and respond to yet another dimension of human life beyond those commonly identified with leader-follower relationship. This response led to the emergence of theory of spiritual leadership. According to Fry (2003), spiritual leadership includes teaching the followers correct principles and the application of techniques that enable self-governance. He further mentions that spiritual leadership is a causal theory based on an intrinsic motivation model that incorporates vision, hope, faith, and altruistic love; theories of workplace spirituality; and spiritual survival and well-being. Spiritual leadership, as a model for organizational development and transformation, can guide the evolution of positive organizations in which human wellbeing and organizational-level performance can not only coexist but also be optimized. Spiritual leaders clarify followers' moral identities, strengthen, and deepen their commitments (Fairholm, 1996) for organizational success. 
Many studies have been carried out to determine the impact of type of leadership to the employee performance and how leadership behaviours can be used to influence employees for improved organizational outcomes (Lok and Crawford, 2004; Fry, 2003). The studies mainly focused to discovering which behaviours and circumstances that must be joined to produce effective group and organizational outcomes especially organization commitment and job satisfaction. Leadership style, environment, individual demographic background, and interpersonal relationships can influence the employee job satisfaction (Lin, 2004). Employee job satisfaction is also among the important factors that measure the perception of the effectiveness of their leader leaderships (Chen, 2008). While research on the impact of other leadership styles to the employee job satisfaction is abundant; little attention is given to the research on the impact of spiritual leadership to the employee job satisfaction. Thus, this study tries to fill the gap and hopefully this will contribute to the existing literature.

The objectives of this study are as follows:

- to briefly highlight the Theory on Spiritual Leadership;

- to determine measures of job satisfaction; and

- to suggest a framework on the relationship between spiritual leadership and job satisfaction in a multidimensional approach

\section{Literature Review}

Studies in spiritual leadership are still considered scarce (Usman and Danish, 2010; Aydin and Ceyland, 2009). There is emerging evidence that spiritual values and practices are related to leadership effectiveness (Reave, 2005). Effective leaders have higher levels of employee commitment, productivity, and customer satisfaction when employees' spiritual needs are met and aligned with organizational vision and values (Fry et. al, 2003; Malone and Fry, 2003). These spiritual needs are intangible concepts that stimulate their actions for better organizational outcomes. Most of the leadership literature investigates specific characteristics of an effective leader and the importance of leadership development in creating successful leaders for improved organizational performance. In the past decade there has been a heightened curiosity concerning the impact of spirituality on leadership practices (Justin, 2008). However, there are a lot of debates on the exact meaning of the term spirituality. Thus far, no consensus has been reached for a single, concrete definition of spirituality.

East (2005) in his grounded study on how spirituality in the workplace impacts a person's job satisfaction revealed that all of the collected evidence from his research points to a strong and significant relationship between workplace spirituality and a person's job satisfaction and/or job dissatisfaction. Findings of his study argue for leaders to provide ways to implement workplace spirituality for the purpose of employee job satisfaction. Studies also attempt to relate spiritual leadership with other mediating factors to job satisfaction in an organizational set up. Aydin and Ceyland (2009) have constructed an original model and carried out a research analysis to investigate the employee satisfaction in terms of organizational culture and spiritual leadership in the metal working manufacturing company in Turkey. The survey had been conducted on 578 employees of the related industry. The results indicated that the constructed model was significant and employee satisfaction had positive significant correlations with organizational culture and spiritual leadership.

The Theory of spiritual leadership: The theory of spiritual leadership is developed within an intrinsic motivation model that incorporates vision, hope/faith, and altruistic love, theories of workplace spirituality, and spiritual survival; where the spiritual survival variables are meaning/calling and membership (Fry et. al, 2003). Spiritual leadership taps into the fundamental needs of both leader and follower for spiritual survival so they become more organizationally committed and productive (Fry, 2003, Fry et. al., 2003). The purpose of spiritual leadership is to create vision and value congruence across the strategic, empowered team and individual levels and, ultimately, to foster higher levels of organizational commitment and productivity.

Vision is considered to be the essence of leadership and has been defined as an idealized future goal state (Conger, 1999; Yukl, 2001). Strange and Mumford (2002) argue that vision involves a set of beliefs about how people should act, and interact, to make manifest some idealized future state. Vision mapped out the aspiration of the organization wants to be in the near to distant future. Altruistic love is defined as a sense of wholeness, harmony, and well-being produced through care, concern, and appreciation for both 
self and others. Underlying this definition is the values patience, kindness, lack of envy, forgiveness, humility, selflessness, self-control, trust, loyalty, and truthfulness (Fry, 2003). Faith is more than merely wishing for something. It is based on values, attitudes, and behaviours that demonstrate absolute certainty and trust that what is desired and expected will come to pass (Fry, 2003). People with hope/faith have a vision of where they are going, and how to get there; they are willing to face opposition and endure hardships and suffering, to achieve their goals (MacArthur, 1998). According to Fry (2003), meaning/calling is suggesting that organization members believe the job they do is important and meaningful for them and it makes a difference in the people's lives, whereas calling was conceptualized as work performed out of a strong sense of inner direction and divine inspiration to do morally responsible work. Membership means that the organization understands the members and appreciates them. In other words, when leaders recognize employee contributions, employees feel better about the organization, they feel more of a sense of community, and they are more likely to stay with the organization and continue to contribute (Reave, 2005).

Job satisfaction: There are numerous definitions on job satisfaction by writers since this concept has become a great concern to many organisations in their quest for competitiveness and survival in today's business environment. Porter and Lawler (1968) define job satisfaction as an undimensional construct; that is, one is generally satisfied or dissatisfied with one's job. They further explain that job satisfaction is people's affective (emotional) response to their current job conditions. Aamodt (1996) defines job satisfaction as "the attitude an employee has toward his job". When we look further the correlation of job satisfaction and attitude, we would agree that there is a strong correlation between these two concepts.

Global job satisfaction reflects an individual's overall feeling towards his or her job. In addition, people may express feelings about particular aspects or facets of their jobs. This is what Smith et. al., (1969) argue that job satisfaction is actually multidimensional as opposed to Porter and Lawler's theory. The job setting is viewed as being composed of different constituent parts with which an individual may be either satisfied or dissatisfied. People may be more or less satisfied with their job, supervisor, pay, workplace or anything related to their needs. Smith et. al., (1969) have developed a Job Descriptive Index (JDI) and categorised the overall measure of job satisfaction into satisfaction with work, promotion, pay, supervision and co-workers. These facets are considered the dominant factors of job satisfaction/dissatisfaction to the employees.

Consequences of job dissatisfaction: As we discussed earlier, people view job satisfaction in two ways; global and facet. Global job satisfaction reflects an individual's overall feeling towards their job, but some people may express feelings about particular aspects of facets of their job. Quinn and Mangione (1973) suggest that there are series of different conceptual models of the processes that lead to job satisfaction or dissatisfaction. According to them, we have to consider two psychological components: first, the individual values with respect to work in general; and second, the extent to which the needs associated with these values are being met by his present job. They added that, for example, if a person places a great deal of importance on having freedom to decide how he does his job, then he reports that his present job does not provide him this freedom, then this aspect of job is a source of dissatisfaction. For another individual who places little value on such freedom, the absence of such thing would not affect his job satisfaction. Roznowski and Hulin (1992) maintain that low levels of job satisfaction create one or a combination of four types of undesirable behaviour. First, dissatisfied individuals may attempt to increase job outcomes by stealing, using work time to pursue personal tasks or by moonlighting. Second, they may withdraw from job psychologically as shown by behaviour like not attending meetings, drinking on the job, or wandering about trying to look busy. Third, dissatisfied employees may practice behavioural withdrawal from the job as in absenteeism, turnover, or early retirement.

Studies on the impact of type of leadership to employee performance: There are many studies on the impact of type of leadership to the employee performance. Research on leadership has taken several approaches. Yukl, (1989) found that most research can be classified into four major approaches; 1) Trait approaches; 2) Situational approaches; 3) Power-influence approaches, and 4) Behavioural approaches. Mixed results have been obtained in attempting to improve the effectiveness of leaders. None of the approaches has been found to very effective in all situations (Bass, 1990).

Many studies in leadership attempt to relate the quality of leaders in relation with the employees' performance. Lee (2005) found that transformational leadership has positive association with the dimensions of Leader-Member Exchange (LMX) and organizational commitment. He further suggested 
that LMX quality is found to have a causal effect to mediate the relationship between leadership and organizational commitment. This further supports the findings of Rowden, (2000) on the relationship between charismatic leadership and organizational commitment. Study suggested that the leader's sensitivity to member needs is clearly related to organizational commitment. It is unlikely that someone would be committed to an organization where its leader was not attuned to his or her needs. Lok and Crawford (2004) examined the effects of organizational culture and leadership styles on job satisfaction and organizational commitment in samples of Hong Kong and Australian managers. They found that for the combined samples, innovative and supportive cultures, and a consideration leadership style, had positive effects on both job satisfaction and commitment, with the effects of an innovative culture on satisfaction and commitment, and the effect of a consideration leadership style on commitment being stronger in the Australian sample. It is found that leadership styles are significantly related to the employees' job satisfaction.

Most studies on leadership styles also found to be positively related to the employees' satisfaction. Employees tend to be happy and willing to commit further in their work if the behaviour of supervisor is acceptable to them. In her study of the relationship between manager's leadership style and employee job satisfaction in Beijing Software Companies, Chen (2008) utilising a Paternalistic Leadership Scale which contains items on Moral, Benevolent and Authoritarian leadership, and Job Descriptive Index (JDI) revealed that perception of moral and benevolent leadership style showed strongest correlation with satisfaction with opportunities for promotion, while authoritarian leadership style was negatively correlated with satisfaction with both supervision and co-worker. It also found that perception of moral leadership correlated with most of the job satisfaction factors. Leadership is a central role in the organization's pursuit of excellence. Many studies had agreed employee performance is positively related to the job satisfaction and the leaders are those who motivate the employee to perform their tasks. Mosadegrad (2006), in a study of relationship between managers' leadership style and employees' job satisfaction at Isfahan University Hospitals in Iran, found that the dominant leadership style of managers was participative. Employees demonstrated less satisfaction with salaries, benefits, work conditions, promotion and communication and more satisfaction with factors such as the nature of the job, coworkers and supervision. There was significant correlation between the use of leadership behaviours and employees job satisfaction.

\section{Proposed Conceptual framework}

This study proposes the conceptual framework of the relationship between the variables of spiritual leadership and job satisfaction in a multi dimensional approach. This is illustrated in Figure 1.

Based on our review of the related literatures, we have constructed nine hypotheses to test:

H1: $\quad$ There is a significant positive relationship between vision, hope/faith and job satisfaction

H2: There is a significant positive relationship between altruistic love and job satisfaction

H3: There is a significant positive relationship between meaning/calling and job satisfaction

H4: $\quad$ There is a significant positive relationship between membership and job satisfaction

H5: $\quad$ There is a significant positive relationship between spiritual leadership and work aspect of job satisfaction

H6: There is significant positive relationship between spiritual leadership and promotion/pay aspect of job satisfaction

H7a: There is a significant positive relationship between spiritual leadership and supervision aspect of job satisfaction

H7b: There is a significant positive relationship between spiritual leadership and co-workers aspect of job satisfaction

H8: There is a significant positive relationship between spiritual leadership and overall job satisfaction

H9: There is a significant negative relationship between spiritual leadership and intention to quit 
Figure 1: Proposed Conceptual Framework

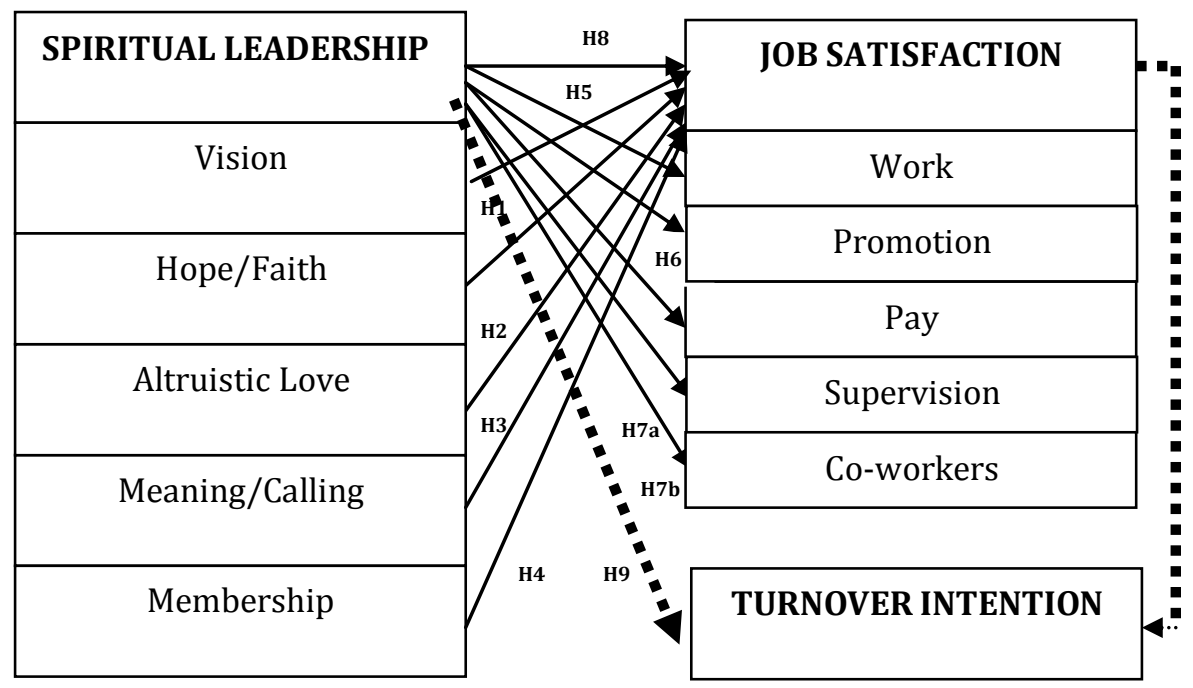

\section{Methodology}

Research Design: This study will be using primary data by means of a questionnaire for data collection. Questionnaires will be distributed personally to enable us to get the related information. Respondents will take roughly 30 minutes to answer the questions.

Sample and data Collection: We will draw our samples from top and middle management of Shipyard companies situated in the East Coast region of Malaysia. We hope to obtain at least 200 respondents from these shipyard companies.

Research Instrument: The questionnaires were designed based on three main scales as in Table 1 below:

Table 1: Scales Adapted in the Study

\begin{tabular}{llc}
\hline \multicolumn{1}{c}{ Scales } & \multicolumn{1}{c}{ Adapted From } & No. of Items \\
\hline Spiritual Leadership & Fry, 2005 & 26 \\
Job Satisfaction & Smith et. al. 1969 & 25 \\
Turnover Intention & Jaramillo et. al. 2009 & 4 \\
\hline
\end{tabular}

There are four parts in the questionnaire. Details are as follows:

- For the demographics gender, age, educational background, years of working, work experience and job description will be asked and respondents will tick the respective boxes;

- For Spiritual Leadership, the respondents will be asked to rank from 1 strongly disagree to 5 strongly agree based on 5 point Likert scale;

- For Job Satisfaction respondents will be asked to rank from 1 agree, 2 not sure and 3 disagree;

- For Turnover Intention a 5 point Likert scale of 1 strongly disagree, 2 disagree, 3 neither disagree nor agree, 4 agree and 5 strongly agree will be used.

\section{Data Analysis and Expected Results}

Descriptive statistics and correlation analysis will be used to determine whether there are significant relationships exist between spiritual leadership, job satisfaction and turnover intention. Pilot tests will be carried out first to test the validity of our questionnaires. Fifty questionnaires will be distributed to marine managers in Kemaman, Terengganu. We hope that the results will be consistent with other researchers as mentioned earlier. 


\section{Conclusion}

Spiritual leadership has emerged in the midst of people searching for something for their spiritual survival in today's chaotic business environment. For organizations that aim to excel and gain a competitive advantage, they have to retain a team of highly motivated and satisfied employees to attain optimum performance. A leaders' quality have become a paramount important to motivate and foster a maximum organizational commitment. The spiritual leadership components that consist of vision, hope/faith, altruistic love, meaning/calling and membership contain high value-based leadership type which can trigger and change employees' action by practicing care and concern and intrinsically motivate them to perform willingly for the good of the organization. Job satisfaction of the employees is a very important determinant of high performance. Various facets of job satisfaction have to be studied to discover the strength and weakness of each aspect that attributed to its level. A leadership and job satisfaction component is a good match as 'leader/follower' relationship to better predict the organizational outcomes. Spiritual leadership qualities that been explored in this paper can be assessed in relation to the component of job satisfaction to discover a match between these two concepts.

The scales that will be adapted in this study are based on the work of Fry (2005) for measures of spiritual leadership, Smith et. al. (1969) for measures of job satisfaction, and Jaramillo et. al. (2009) for measures of turnover intention. Based on these measures, we propose a framework to be employed in this study. Hence, nine hypotheses are formulated and will be tested. We will first carry out a pilot test on fifty marine managers to test the validity of the instruments. We believe that the results from this study may be useful to marine companies as well as other companies in planning their roadmap to their future success. The leadership styles and how it influences job satisfaction and turnover will be understood and applied in the marine companies as well as other companies.

\section{References}

Aamodt, M., G. (1996). Applied Industrial/ Organizational Psychology (4th Edition). Boston, MA: Brooks/Cole.

Aydin, B. \& Ceyland, A. (2009). A research analysis on employee satisfaction in terms of organizational culture and spiritual leadership. International Journal of Business and Management, 4(3), 159168.

Barnett, T., (2011). Leadership Theories and Studies, Reference for Business, Encyclopedia of Business $2^{\text {nd }}$ Ed.

Bass, B., M. (1990). Bass and Stodgill's handbook of leadership: Theory, research and applications, (3rd ed.), New York: Free Press.

Chen, X. (2008). The relationship between manager's leadership style and employee job satisfaction in selected Beijing Computer Software Companies, Unpublished PhD dissertation, University of the Incarnate Word, San Antonio, Texas.

Conger, J., A. (1999). Charismatic and transformational leadership in organizations: An insider's perspective on the developing streams of research. The Leadership Quarterly, 10(2), 145-180.

East, T., J. (2005). A grounded study on how spirituality in the workplace impacts a person's job satisfaction, Unpublished PhD dissertation, Capella University, Minneapolis, Minnesota.

Fairholm, G. W. (1996). Spiritual leadership: fulfilling whole-self needs at work, Leadership \& Organizational Journal, 17(5), 11-17.

Fry, L. W., Vitucci, S., \& Cedillo, M. (2003). Transforming the army through spiritual leadership, Unpublished manuscript. Tarleton State University-Central Texas, Killeen, TX. Available at http://www.tarleton.edu/ fry/ resources.html.

Fry, L., W. (2005). Toward a theory of ethical and spiritual well-being, and corporate social responsibility through spiritual leadership, In C. Dunne, R.A. Giacolone \& C.L. Jurkiewicz (Eds.), Positive psychology and corporate responsibility. Greenwich, CT: Information Age Publishing.

Fry, L., W. (2003). Toward a theory of spiritual leadership, The Leadership Quarterly, 14(6), 693-727.

Jaramillo, F., Grisaffe, D., B., Chonko, Lawrence B., \& Roberts, J., A. (2009). Examining the impact of servant leadership on salesperson's turnover intention, Journal of Personal Selling \& Sales Management; 29(4), 351-365.

Justin, R. (2008). Spirituality Among Public School Principals and its Relationship to Job Satisfaction and Resiliency. Unpublished dissertation, Union University School of Education. 
Lee, J. (2005). Effects of leadership and leader-member exchange on commitment, Leadership \& Organization Development Journal: 26(8), 655-672.

Lin, L. C. (2004). The relationship between manager's leadership style and employee job satisfaction in Taiwan fashion retail department stores, Retrieved November 2008, from Proquest Digital Dissertations \& Theses database (Publication No. AAT 3133651).

Lok, P. \& Crawford, J. (2004). The effect of organizational culture and leadership style on job satisfaction and organizational commitment: A cross-national comparison, Journal of Management Development, 23(4), 321-338.

MacArthur, J., F. (1998). In the footsteps of faith. Wheaton, IL: Crossway Books.

Malone, P., \& Fry, L. W. (2003). Transforming schools through spiritual leadership: A field experiment, Paper presented at the 2003 Meeting of the Academy of Management, Seattle, WA.

Mosadeghrad, A., M. (2003). The role of participative management (suggestion system) in hospital effectiveness and efficiency, Research in Medical Science. 8(3), 85-89.

Mosadeghrad, A., M. (2006). A study of relationship between managers' leadership style and employees' job satisfaction, Leadership in Health Services, 19(2), pp. 11-28.

Porter, L., W. \& Lawler, E., E (1968). Managerial attitudes and performance, Homewood. Irwin Dorsey (128).

Quinn, R. P., \& Mangione, T. W. (1973). Evaluating weighted models for measuring job satisfaction: A Cinderella story. Organizational Behaviour and Human Performance, 10, 1-23.

Reave, L. (2005). Spiritual values and practices related to leadership effectiveness, The Leadership Quarterly, 16(5), 655-687.

Rowden, R. W. (2000). The Relationship between charismatic leadership behaviours and organizational commitment. Leadership Organizational Development Journal. 21(1), 30-35.

Roznowski, M, \& Hullin, C. (1982). Job Satisfaction: How People Feel About Their Jobs and How it Affects Their Performance. New York, Lexington Books (123-163).

Skansi, D. (2000). Relations of managerial efficiency and leadership styles - empirical study, Hrvatska elektroprivreda, Management, 5(2), 51-67.

Smith, P. C., Kendall, L. M., \& Hullin, C. L. (1969). The measurement of satisfaction in work and retirement: A strategy for the study of attitudes. Chicago Rand McNally.

Strange, J. M., \& Mumford, M. D. (2002). The origins of vision: Charismatic versus ideological leadership. The Leadership Quarterly, 13, 343-378.

Strange, J. M. \& Mumford, M.D. (2005). The origins of vision: effects of reflection, models and analysis, The Leadership Quarterly, 16(1), 121-48.

Thompson, W., D. (2000). Can You Train People to Be Spiritual? Training and Development, 54 (12), 18-19.

Usman A. \& Danish, R. Q. (2010), Spiritual Consciousness in Banking Mangers and its Impact on Job Satisfaction. International Business Research, 3(2), 65-72.

Yukl, G. A. (1989). Leadership in Organizations, Prentice-Hall. Englewood Cliffs, NJ.

Yukl, G. J. (2001). Leadership in organizations. Englewood Cliffs, NJ7 Prentice-Hall. 